\title{
Comparative Life-Cycle Analysis of Two Repair Measures for Chloride Contaminated Concrete Structures
}

\author{
Sylvia Keßler \\ Helmut-Schmidt-University/ University of the Federal Armed Forces Hamburg, Chair of \\ Engineering Materials and Building Preservation, Holstenhofweg 85, Hamburg, 22043, Germany, \\ sylvia.kessler@hsu-hh.de
}

\begin{abstract}
Often the mere mention of the word "Sustainability" leads to the reflection of the effect of our actions on environment and future generations. Especially the application of reinforced concrete as the most used construction material has a huge impact on a society being sustainable. Thus, the construction industry focuses on the design of environmentally- and resource-friendly buildings. However, due to our aging infrastructure and expected high demand of maintenance and repair in future, a further look on the sustainability of different repair measures for reinforced concrete structures has been neglected in the past. This paper presents a comparative case study of the life-cycle analysis of two different repair measures for reinforced concrete affected by chloride-induced corrosion. The selected repair measures - removal of the chloride-contaminated concrete and cathodic protectionare the most common repair measures in Germany. In future way concrete repair measure could be selected not only by the costs but as well by their environmental impact. This paper provides first information to achieve this target.
\end{abstract}

Keywords: Reinforced Concrete Structures, Repair Measure, Life-Cycle-Analysis, Reinforcement Corrosion.

\section{Introduction}

Our infrastructure is the backbone of our society and economy. Bridges and tunnels maintain our mobility and enable the transportation of constantly increasing number of goods. Additionally, in dense inner city areas multi-storey and underground car parks are of greatest importance to provide space keeping the traffic flowing. However, most of these reinforced concrete structures have achieved already their designed service life or the designed service life is shorten due to durability issues. Consequently, these structures need repair measures.

Especially, chloride-induced corrosion require maintenance actions as major reason for structures deterioration. Chlorides from sources such as de-icing salt or marine environment penetrate into the porous concrete and as soon as a critical chloride concentration accumulates at the reinforcement, corrosion initiation becomes likely. Consequences of reinforcement corrosion are the loss of rebar cross section and in an advanced stage cracking and spalling of the concrete cover. Thus, this deterioration process impairs the serviceability and the load bearing capacity of our infrastructure.

The standard, EN 1504-9 provides several repair principles for chloride-contaminated concrete structures with the aim to stop and to prevent reinforcement corrosion. The most commonly applied repair principles are:

- Principle 7: Preservation or restitution of the coat passive layer (RP)

- Principle 8: Increase of concrete resistance (IR) 
- Principle 10: Cathodic protection (CP)

The principles 9 (cathode control) and 11 (anodic areas control) have no conceptual meaning in Germany since their effectiveness have not been proven yet.

The approach achieving corrosion control of each repair measure is different. For preserving and restoring the reinforcement's passivity, the chloride-contaminated concrete is removed and replaced by new, alkaline and chloride-free concrete. The high alkalinity of the fresh concrete leads to the repassivation of the former anodic areas and reinforcement corrosion is impaired. The repair measure is by far the most common one even though it is a significant intervention in the structure's integrity.

The increase of concrete resistance aims to dry out the concrete, e.g. by application of a concrete coating, until the electrolytic corrosion process is no longer possible and the corrosion velocity comes to a negligible rate.

In recent years, cathodic protection systems gain more and more attention and one standard (EN ISO 12696) focuses exclusively on this repair measure. Cathodic protection suppresses the anodic reaction by applying an electric potential. The polarization of the reinforcement forces the reinforcement to act electrochemically as a cathode. Consequently, no anodic reaction - no loss of cross section - can take place even though the chloride concentration is on a critical level. In addition, cathodic protection diminishes the driving potential between former anodic and cathodic rebar areas providing supplementary protection against corrosion.

\section{Each repair princip}
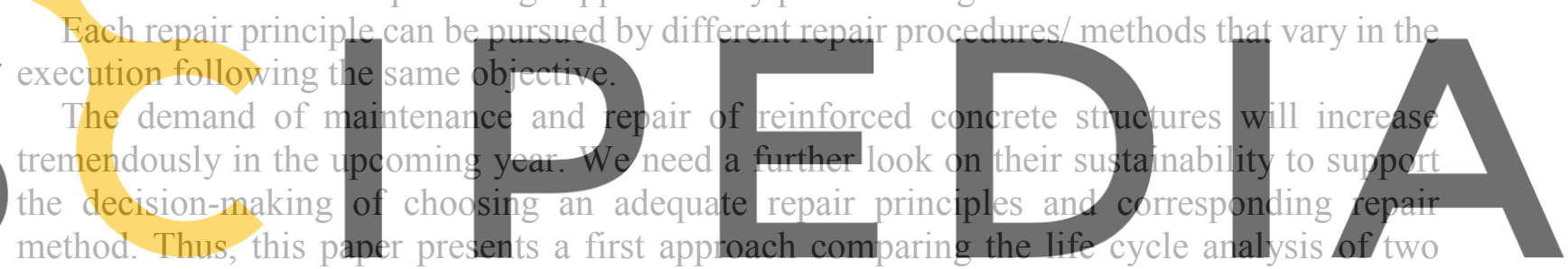

repair methods for a specific case study. The aim is to evaluate the category indicators (a) global

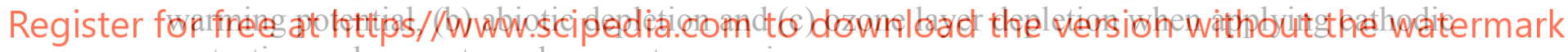
protection and concrete replacement as repair measure.

\section{Life Cycle Assessment}

The Paris Agreement from the United Nations urges especially the developed countries to deliver an overall mitigation in global emissions. This goal is only achievable, if we are aware of our environmental impacts. This applies in particular to the construction industry as one of the major emitters due to e.g. the energy-intensive production of cement/ concrete and steel. One option to identify the most sustainable repair measures of reinforced concrete structures is the implementation of a life cycles assessment (LCA) according to DIN EN ISO 14040 and DIN EN ISO 14044.

The LCA study consists of several steps starting with the definition of the scope followed by the inventory analysis and impact assessment and ends with the interpretation of the results. The scope of the LCA should be described as precise as possible including all considered boundary conditions to ensure consistency. The inventory analysis collects all data involved such as the quantification of the relevant inputs and outputs of the repair action during the defined life cycle. The inputs and outputs should be broken down to the elementary level. 
During the impact assessment phase, the impact of the repair measure on the environmental is estimated based on category indicators. Impact categories are the consumption of primary raw materials; water consumption, primary energy consumption, global warming potential, acidification potential, photochemical ozone creation potential and material recyclability. The final step is the discussion of the outcome taken into account the objective of the study.

Conclusions and recommendations complement the LCA study leading to a clear decisionmaking basis for more sustainable rehabilitation of concrete structures.

\section{Case Study}

The objective of the life-cycle assessment of two different repair measure is to support future decision-making for the most sustainable repair measure. Secondly, the study aims to identify missing data we need to collect in future to enable comprehensive sustainability analysis of repair measures.

\subsection{Functional Unit}

The functional unit for this sustainability assessment of repair measures is a very common constructive element: one square meter of reinforced concrete plate. This plate could be e.g. part of a bridge superstructure or part of a multi-storey car park. Consequently, the functional unit is assigned to exposure class XD3 (DIN EN 206), which considers chloride exposure from de-icing salts in combination with cyclic wetting and drying. Since the element is part of an aged, deteriorated struc about $55 \mathrm{~mm}$ and there water-to-binder ratio 75 years with a target to a corrosion probability of 30
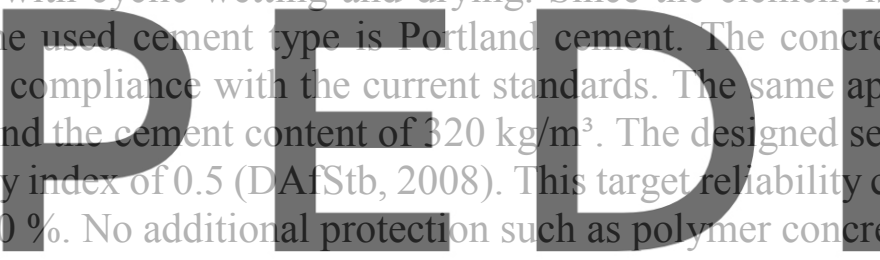

are applied and possible cracking of the concrete cover, respectively crack repair is neglected.

\section{Register for free at https//www.scipedia.com to download the version without the watermark}

First, a probabilistic service life prediction assists the decision making to estimate when and how often the functional unit requires repair actions. Figure 1 shows the results of the initial probabilistic service life prediction according to fib Model Code for Service Life Design (fib bulletins 34 and 76). 


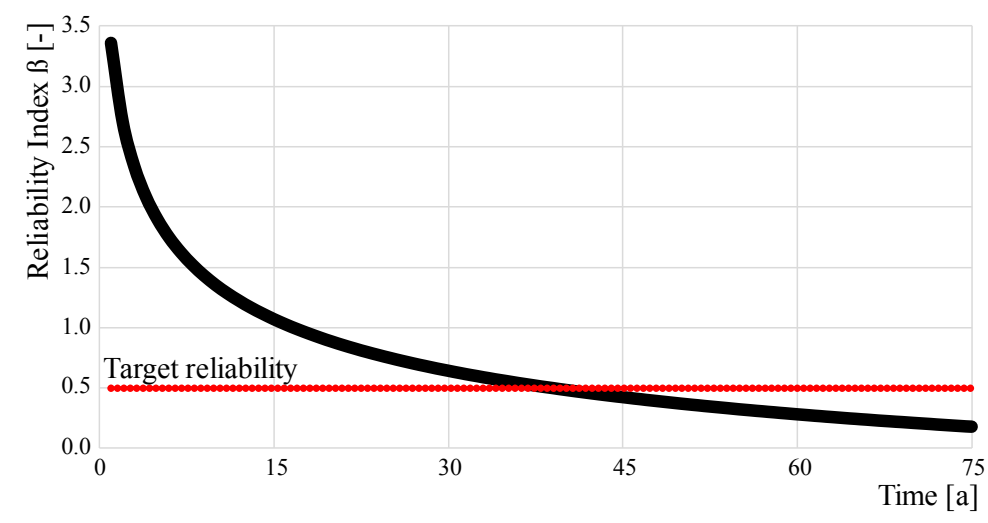

Figure 1. Service life assessment of the case study.

Even though, the durability design of the functional unit complies with the standards the target reliability of $\beta=0.5$ is achieved after around 40 years. This result is in line with literature data (fib bulletin 76), which revealed that the durability design rules cannot ensure consequently a design service life of normally 50 years without the need of repair actions. However, the presented case study requires repair action within the designed service life of 75 years.

\subsection{Repair Measures}

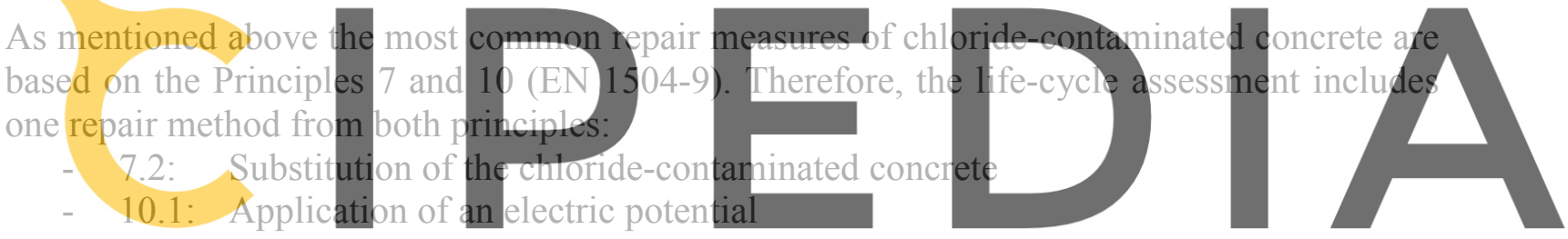

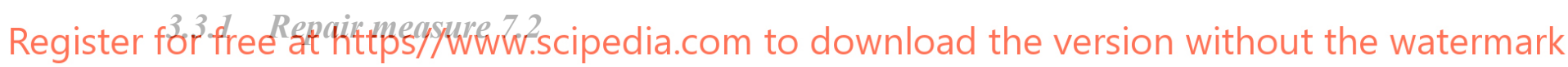
Roughly, the application of the repair method 7.2 consists of the mechanical removal of the chloride-contaminated concrete and the refill with fresh and alkaline concrete until the former or newly requested concrete cover is achieved. This procedure can be an intrusive intervention in the structure's integrity. On the other hand, it is an effective method to inhibit reinforcement corrosion.

However, very little information is available on the service life of this repair measure. Tilly and Jacobs (Tilly et Jacobs 2007) analyzed 230 case studies of concrete repair measures. Concrete replacement were effective only in rd. $50 \%$ of the investigated use cases. The authors listed several reasons for the failure: inappropriate measure or material, execution error, nonconformance of the specifications etc.. After 5 years in service, $20 \%$ of the repair measure needed repair measure, $55 \%$ within 10 years and $90 \%$ within 25 years. Polder et al. (Polder et al. 2016) confirmed the results of Tilly and Jacobs with data of a Dutch study.

\subsubsection{Repair measure 10.1}

Here, the application of the electric potential is implemented through an impressed current cathodic protection (ICCP) system, where an external power supply generates large potential 
differences to enable the current flow needed for corrosion protection. In the electric circuit, the reinforcement acts as a cathode whereas the anode system is applied on the concrete surface layer. Several anode systems are on the market. The most common anode systems for plate elements are mixed metal oxide/titanium (MMO/Ti) anodes in shape of ribbons or meshes, which must be embedded in cementitious material to enable the electrolytic contact to the concrete. The application require several working steps, however, it maintains the structures integrity since the chloride-contaminated concrete remains in the structure.

The whole ICCP system needs to be applied only once and the effectiveness of the corrosion protection is monitored. Nevertheless, the systems includes many electrical components such a power supplies or electrical transformers with limited service life under continuous use. Their replacement is easy to handle and need to be considered for the life-cycle analysis.

The ISO 12696 indicates a service life of the NMO/Ti anodes in the range of 25 to 100 years in dependence of the range of the current density. Polder et al. (Polder et al. 2016) estimated the service life of a CP system of about 50 years and Wilson et al. (Wilson et al. 2013) of about 10 to 120 years, excluding the electric components, which need replacement at least every 20 years. Nevertheless, it is important to mention that cathodic protection systems on concrete structures is a relatively new repair measure (started in the 90's) and current experiences are based on the early, more vulnerable cathodic protection systems.

\subsubsection{Repair measure cycles}

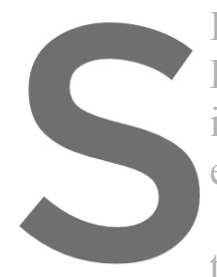
It appears that very litthe information is availabie on the dur
Based on the literature it is very likely that repair measure nee
inadequate material of poor execution. These effects are very
estimation of repair cycles during a service life of a concrete st
The installation of the CP systems with ribbon anodes tak than the replacement of ride-contaminatc system can only be applied when the corrosion damage is not in an advanced stage showing

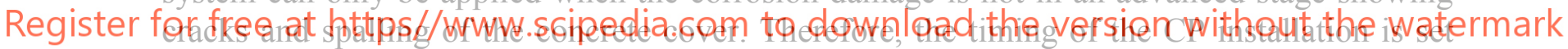
when the reliability index is 1.3 (corrosion probability $10 \%$ ) after 11 years, see Figure 1. Every 20 years, in total for two times, all electronic components will be renewed. In contrast, the time of the concrete replacement corresponds to the time when the target reliability is reached after 40 years. It is assumed that the new concrete shows the same chloride penetration resistance as the former one. Therefore, the repair measure takes place only once until the end of the designed service life of the structure.

\subsection{The Inventory Analysis}

The objective of the inventory analysis is the collection of all relevant environmental information on the used material and the execution process for each repair measure. Each step includes if necessary the consumption of energy and water and the consideration of the transport (fuel, distance) of the needed material.

\subsubsection{Relevant information of repair measure 7.2}

The execution of the repair measure 7.2 consists of the following steps, which need to be considered for the LCA: 
- Removal of concrete with ultra-high water pressure jetting

- Production of concrete

- Processing of the fresh concrete

- Disposal of concrete

\subsubsection{Relevant information of repair measure 10.2}

The following inputs and outputs are part of the installation of a cathodic protection system on reinforced concrete with ribbon anodes:

- Production of the titanium anodes

- Production of the embedding mortar

- Production of reference electrodes

- Production of the Electronic components (e.g. power supply, transformer and rectifier, control devices, data management systems and connection boxes, cables)

Concrete milling

Installation of the ribbon anodes

Installation of the reference electrodes

Installation of the electric contact to the reinforcement

Processing of the embedding mortar

Disposal of concrete

Disposal of electronic waste

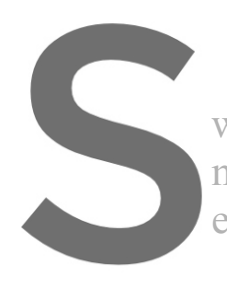

It is obvious, that the working steps that the

much higher for the concrete

electric components.

Sometimes, during a conerete removal

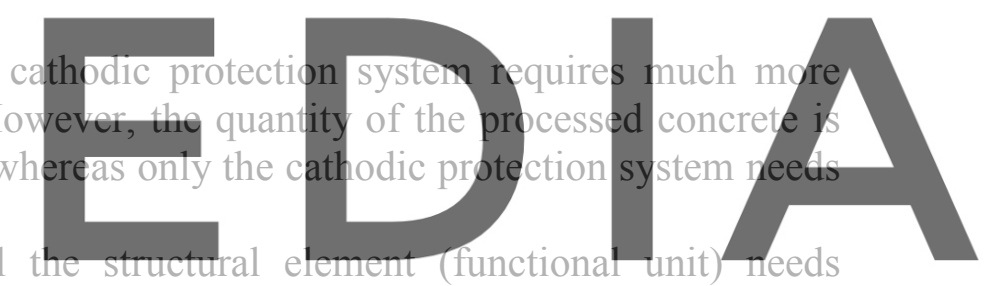

additional support for static reasons. This step is not included in this analysis.

Register for free at https//www.scipedia.com to download the version without the watermark

3.5 Results

The software package SimaPro (Version 8.4.0.0) with the underlying databases of ecoinvent (Version 3) supported the evaluation of this LCA study using the CML-IA baseline method. The following results show the comparison of both repair measures for selected impact categories considering a service life of 75 years, see Figure 2.

In all three categories, the cathodic protection system shows greater impact on the environment than the concrete replacement measure. The greatest difference between both repair measures is in the global warming potential. Here, the impact of the $\mathrm{CP}$ systems is more than twice the level of the concrete replacement. The reason for this difference is the impact of the replacement (production and disposal) of the electronic components for the cathodic protection system with a value of $158 \mathrm{kgCO}_{2}$ eq. The highest impact on the global warming potential within the concrete replacement has the removal of the old concrete using ultra-high water pressure jetting with a value of rd. $62 \mathrm{kgCO}_{2} \mathrm{eq}$.

The same dependencies apply for the abiotic depletion. Here, the impact of the CP systems is much greater due to the production of the electronic components with a value of $586 \mathrm{MJ}$. Again, the ultra-high water pressure jetting during concrete removal has major impact on the 
abiotic depletion of the concrete replacement. The difference between both repair measures is less pronounced considering the ozone layer depletion.

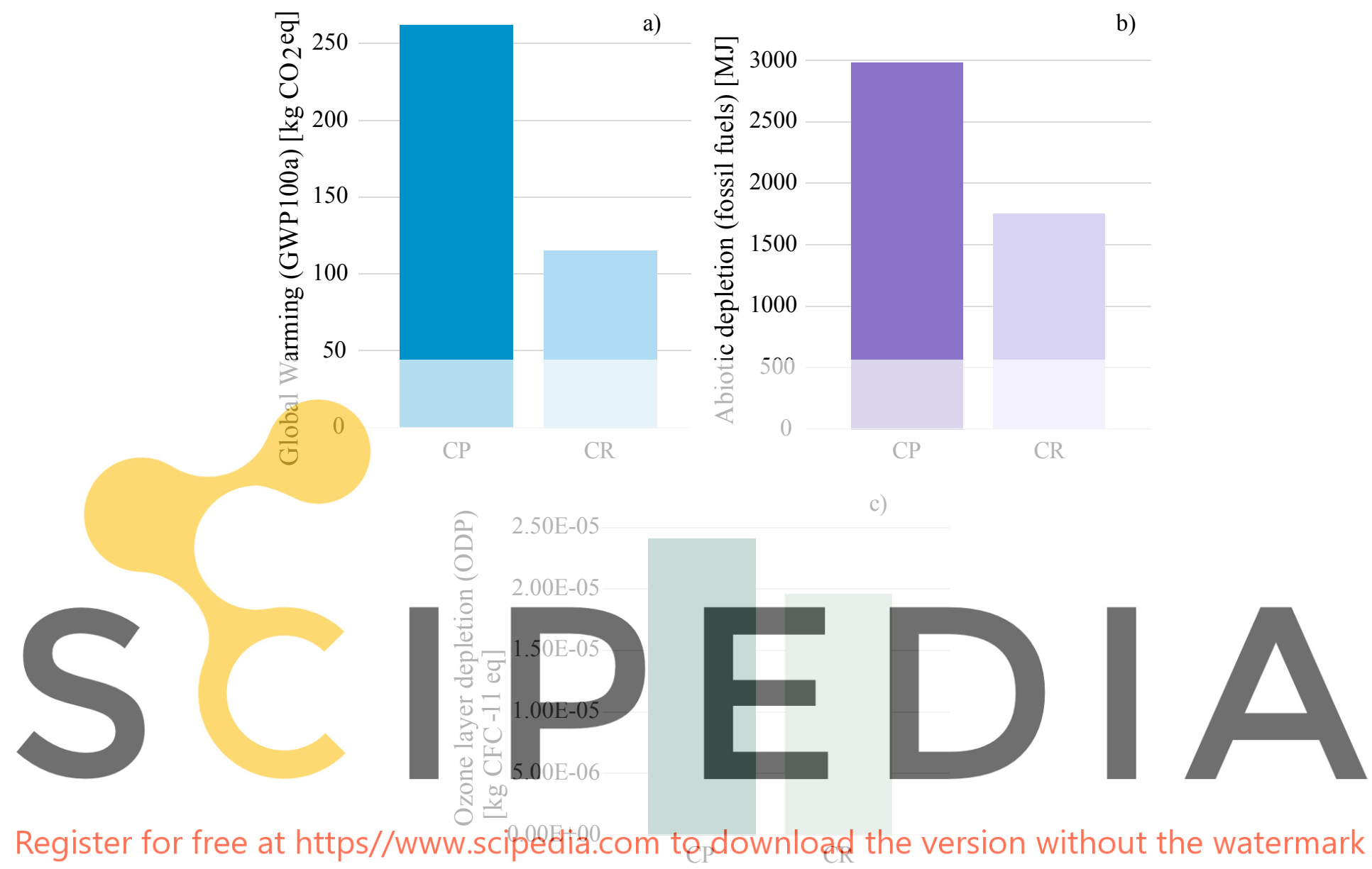

Figure 2. The comparison of the (a) global warming potential, (b) abiotic depletion and (c) ozone layer depletion of the two repair measures CP (cathodic protection) and CR (concrete replacement) on a reinforced concrete plate after a service life of 75 years.

However, the presented results are only of preliminary nature and do not provide a comprehensive study. Very often, the concrete surface needs an additional protection against ingress of chlorides such as polymer coatings if no $\mathrm{CP}$ system is installed. These coatings need also replacement in certain intervals. Thus, the consideration of a polymer concrete coating would lead to different LCA results. Furthermore, the service life of the concrete structure and the service life of the repair measure itself have a huge effect in the LCA outcome.

Nevertheless, this study provides a preliminary insight on the environmental impact on repair measures. Even though, the concrete replacement requires the removal and refill of great volume of concrete it is probably in a lot of use cases the most sustainable repair measure. The impact of electronic components or presumably the impact of polymer concrete coatings is much higher than the pure concrete.

Nowadays, the determination of the adequate repair measure depends mainly on other factors 
such as costs, applicability, remaining service life, and many more. However, in future we should also be aware of the environmental impact of the chosen repair measure as well.

\section{Conclusions}

The following conclusions can be drawn from this specific comparative LCA of the concrete repair measures concrete replacement and cathodic protection.

- The environmental impact of the cathodic protection system is greater than the impact of the concrete replacement when comparing the category indicators global warming potential, abiotic depletion and ozone layer depletion.

- Even though, the concrete replacement consumes much higher quantity of energyintensive concrete it is not necessarily the repair measures with the greatest impact on the environment.

- The high environmental impact of the cathodic protection system is the result of its demand of multiple electronic components.

- The service life of the electronic components is the determining factor of the sustainability of the cathodic protection system.

More generally, more field data on the durability of concrete replacement is required to enable reliable assumptions on repair intervals.
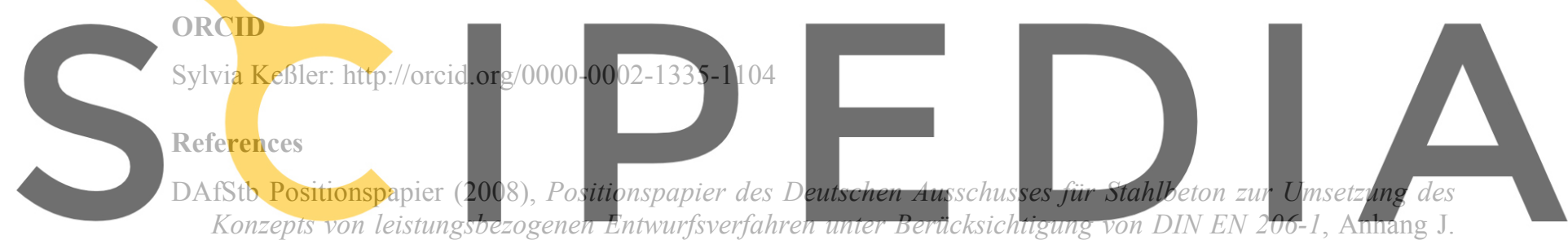

Beton- und Stahlbetonbau 103. Heft 12 .

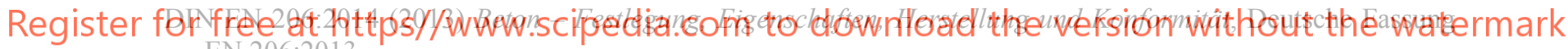
EN 206:2013.

DIN EN ISO 1269 (2017). Cathodic protection of steel in concrete (ISO 12696:2016); German version EN ISO 12696:2016.

DIN EN 1504-9 (2008). Products and systems for the protection and repair of concrete structures - Definitions, requirements, quality control and evaluation of conformity - Part 9: General principles for the use of products and systems; German version EN 1504-9:2008. https://dx.doi.org/10.31030/1471480.

DIN EN ISO 14040 (2009) Umweltmanagement - Ökobilanz - Grundsätze und Rahmenbedingungen, Deutsche und Englische Fassung EN ISO 14040:2006.

DIN EN ISO 14044 (2006) Umweltmanagement - Ökobilanz - Anforderungen und Anleitungen, Deutsche und Englische Fassung EN ISO 14044:2006.

Fédération international du béton (fib). fib Bulletin No. 34 (2006) Model Code for Service Life Design.

Fédération international du béton (fib). fib Bulletin No. 76 (2015) Benchmarking of deemed-to-statisfy provisions in standards: Durability of reinforced concrete structures exposed to chlorides.

Polder, R., Pan, Y., Courage, W. and Peelen, W. (2016) Preliminary study of life cycle cost of preventive measures and repair options for corrosion in concrete infrastructure. HERON Vol. 61 No.1.

Tilly, G. P. and Jacobs, J. (2007) Concrete Repairs - Performance in service and current practice. IHS BRE Press, Backnell.

Wilson, K., Jawed, M. and Ngala, V. (2013) The selection and use of cathodic protection systems for the repair of reinforced concrete structures. Construction and Building Materials 39 19-25. 